\title{
Osmotic water permeabilities of cultured, well-differentiated normal and cystic fibrosis airway epithelia
}

\author{
Hirotoshi Matsui, ${ }^{1}$ C. William Davis, ${ }^{2}$ Robert Tarran, ${ }^{1}$ and Richard C. Boucher ${ }^{1}$ \\ ${ }^{1}$ Cystic Fibrosis/Pulmonary Research and Treatment Center, and \\ ${ }^{2}$ Department of Physiology, The University of North Carolina at Chapel Hill, Chapel Hill, North Carolina, USA
}

Address correspondence to: Richard C. Boucher, 7011 Thurston-Bowles Building, Cystic Fibrosis/Pulmonary Research and Treatment Center, The University of North Carolina at Chapel Hill, Chapel Hill, North Carolina 27599-7248, USA.

Phone: (919) 966-1077; Fax: (919) 966-7524; E-mail: rboucher@med.unc.edu.

Received for publication July 10, 1998, and accepted in revised form March 28, 2000.

\begin{abstract}
Current hypotheses describing the function of normal airway surface liquid (ASL) in lung defense are divergent. One theory predicts that normal airways regulate ASL volume by modulating the flow of isosmotic fluid across the epithelium, whereas an alternative theory predicts that ASL is normally hyposmotic. These hypotheses predict different values for the osmotic water permeability $\left(\mathrm{P}_{\mathrm{f}}\right)$ of airway epithelia. We measured $\mathrm{P}_{\mathrm{f}}$ of cultures of normal and cystic fibrosis (CF) airway epithelia that, like the native tissue, contain columnar cells facing the lumen and basal cells that face a basement membrane. Xz laser scanning confocal microscopy recorded changes in epithelial height and transepithelial volume flow in response to anisosmotic challenges. With luminal hyperosmotic challenges, transepithelial and apical membrane $\mathrm{P}_{\mathrm{f}}$ are relatively high for both normal and CF airway epithelia, consistent with an isosmotic ASL. Simultaneous measurements of epithelial cell volume and transepithelial water flow revealed that airway columnar epithelial cells behave as osmometers whose volume is controlled by luminal osmolality. Basal cell volume did not change in these experiments. When the serosal side of the epithelium was challenged with hyperosmotic solutions, the basal cells shrank, whereas the lumen-facing columnar cells did not. We conclude that (a) normal and CF airway epithelia have relatively high water permeabilities, consistent with the isosmotic ASL theory, and the capacity to restore water on airway surfaces lost by evaporation, and (b) the columnar cell basolateral membrane and tight junctions limit transepithelial water flow in this tissue.
\end{abstract}

J. Clin. Invest. 105:1419-1427 (2000).

\section{Introduction}

Studies of patients with genetic diseases of airway epithelial ion transport, e.g., cystic fibrosis (CF), have strongly suggested that the volume and/or composition of the liquids that line airway surfaces are important components of lung defense $(1,2)$. The interest in the normal physiology of airway epithelia and the dysfunctions in CF led to a large number of studies that have measured airway transepithelial ion transport and properties of the channels, e.g., CFTR (3) and $\mathrm{ENaC}(4)$, that mediate these activities. Much less is known about the final composition of the liquids that line airway surfaces and the contribution of the epithelial water permeability to the modulation of these liquids.

The importance of characterizing the volume and composition of ASL has risen to prominence from studies designed to elucidate the link between CF defects in ion transport and the early pathogenesis of CF airways infections. One hypothesis, the "isosmotic volume hypothesis," emphasizes the importance of the volume, i.e., height, of the liquid lining airway surfaces $(1,5)$. In brief, this hypothesis states that airway epithelia regulate the height of the liquid surrounding cilia, the periciliary liquid (PCL), to facilitate efficient transduction of energy from beating cilia to the mucus layer. In CF, it is predicted that the accelerated rate of transepithelial $\mathrm{Na}^{+}$absorption increases isosmotic volume absorption, which depletes PCL, impacting mucus on airway surfaces that then serves as the nidus for chronic infection (6). In contrast, based on the data of Joris and coworkers (7) and the report of Smith and coworkers (8), a second hypothesis has evolved that focuses on the role of airway epithelia to regulate the composition of ASL. According to this hypothesis, normal airway surfaces absorb salt but not water from airway surfaces to generate a hyposmotic (low salt) ASL, which is required for the activity of salt-sensitive antimicrobial factors against inhaled bacteria (9). In CF, the inability to absorb $\mathrm{Cl}^{-}$ through a $\mathrm{Cl}^{-}$-impermeable airway epithelial cell renders airway surface liquids isosmotic (10) or hyperosmotic (11), effectively inhibiting the activity of antimicrobial factors and leading to chronic infection.

Because the isosmotic volume hypothesis predicts relatively high transepithelial water permeability $\left(\mathrm{P}_{\mathrm{f}}^{\mathrm{T}}\right)$ whereas the hyposmotic airway surface liquid hypothesis predicts low $\mathrm{P}_{\mathrm{f}}^{\mathrm{T}}$, we sought to measure $\mathrm{P}_{\mathrm{f}}^{\mathrm{T}}$ as a parameter to discriminate between these two opposing hypotheses. For these studies, we interfaced well-dif- 
ferentiated cultures of normal and CF bronchial epithelia that contain both lumen facing columnar cells and basement membrane facing basal cells with a confocal microscopy-based system that simultaneously measures bulk liquid flow and epithelial cell height during osmotic challenges. Our goals were to (a) measure osmotic permeabilities in normal airway epithelia and to compare these values to a renal epithelial cell line with a reported low water permeability (12-16); (b) test whether the apical membrane exhibited evidence of water channels and their putative mercury $(\mathrm{Hg})$ sensitivity; and (c) compare $\mathrm{P}_{\mathrm{f}}$ of normal and CF airway epithelia. Finally, the ability to determine simultaneously transepithelial water flow and cell height during anisosmotic solution exposure permitted independent analyses of the time courses of the changes in cell volume and transepithelial water flow.

\section{Methods}

Human bronchial epithelial cell isolation and culture. Human bronchial epithelial (HBE) cells were dissociated with protease XIV (Sigma Chemical Co., St. Louis, Missouri, USA) from portions of mainstem or lobar bronchi (17) representing excess donor tissue obtained at the time of lung transplantation under the auspices of the University of North Carolina Institutional Committee on the Protection of the Rights of Human Subjects. The isolated cells were expanded on tissue culture plastic as described previously (17). First-passage cultures were grown on 12-mm Transwell-Col (T-Col) (Costar, Cambridge, Massachusetts, USA) supports and used when they were fully differentiated and producing mucus (at 2-4 weeks after confluence and the subsequent removal of luminal medium to create "air:liquid cultures"). Transepithelial resistances of the HBE cultures were greater than $300 \Omega \mathrm{cm}^{2}$.

MDCK cells (type II; $R_{T}>1,000 \Omega \mathrm{cm}^{2}$; from American Type Culture Collection, Rockville, Maryland, USA) were grown in DMEM/F12 media supplemented with $10 \%$ FBS. These cells were grown on $12-\mathrm{mm}$ T-Col supports and studied 2-3 days after achieving confluence.

Measurement of transepithelial water flow. Immediately before osmotic water flow experiments, the HBE cells were loaded with calcein by a 30-minute bilateral exposure to $3 \mu \mathrm{M}$ calcein-AM (Molecular Probes Inc., Eugene, Oregon, USA) at $37^{\circ} \mathrm{C}$ (18). Calcein-loaded HBE cell cultures were observed by confocal fluorescence microscopy with the intact T-Col supported on spacers over a $25-\mathrm{mm}$ coverslip that formed the bottom of an open mounting chamber. The spacers, three 0.5$\mathrm{cm}$ lengths of 30-gauge stainless steel tubing, were arranged radially on the coverslip with their inner tips contacting the bottom edge of the T-Col "cup." The space between the T-Col support and the coverslip held a maximum volume of $40 \mu \mathrm{L}$ of isosmotic TESbuffered Ringer's (TBR) solution composed of $140 \mathrm{mM}$ $\mathrm{NaCl}, 5.2 \mathrm{mM} \mathrm{KCl}, 3 \mathrm{CaCl}_{2}$, and 10 TES (pH 7.4). Changes in serosal fluid volume due to transepithelial osmotic water flow directed toward the lumen were routinely calculated from the changes in the fluorescence intensity of Texas Red conjugated dextran (10,000 MW, $0.25 \mathrm{mg} / \mathrm{mL}$; Molecular Probes).

We discovered empirically that the flexible nature of Costar T-Col membranes also allowed the quantification of serosal volume during transepithelial water flow by a measurement of the space between T-Col support and coverslip. Both parameters (bath fluorescence and bath height) were measured by xz-scanning (profile view) confocal microscopy (TCS 4D; Leica, Heidelberg, Germany) and a 40×/0.5-1.0 NA objective (used at an NA of 0.6-0.7). The quantitative relationship between serosal fluid volume and bath height was variable between T-Col supports. Consequently, each T-Col was calibrated before an experiment by sequentially placing a series of measured volumes on the surface of the coverslip, positioning the $\mathrm{T}-\mathrm{Col}$ on each drop using the trineedle spacers, and measuring the resulting distance between the glass and the center of the T-Col support by xz-scanning confocal microscopy (Figure 1b). Image quantification for these and all other experiments was performed using a MetaMorph image processing workstation (Universal Imaging, West Chester, Pennsylvania, USA).

After a quick wash of the luminal surface with TBR before an experiment, the luminal bath was reduced to a volume of approximately $2 \mu \mathrm{L}$ by aspiration. During most experiments, a baseline, xz-scanning confocal image of the residual TBR bathing the lumen $(\sim 20-\mu \mathrm{m}$ thick), the epithelial cells, and the static serosal bath was acquired, after which transepithelial osmotic water flow was initiated with the luminal addition of $200 \mu \mathrm{L}$ of hyperosmotic solution (TBR +150 mosM NaCl or raffinose). This added volume had no instantaneous measurable effect on serosal bath height. Profile images were then acquired for 1 minute at the maximal acquisition rate of the confocal microscope (nominally, 7-second intervals). Transepithelial water flow was determined from the resulting change in fluorescence of the serosal bath, as detailed in Results. The transepithelial osmotic permeability coefficient $\mathrm{P}_{\mathrm{f}}^{\mathrm{T}}$, expressed as micrometers per second, was calculated as, $\mathrm{P}_{\mathrm{f}}^{\mathrm{T}}=\mathrm{J}_{\mathrm{v}}^{\mathrm{T}} / \mathrm{S} \mathrm{V} \mathrm{V}_{\mathrm{W}} \Delta[\pi]^{\mathrm{T}}$, where $\mathrm{J}_{\mathrm{V}}{ }^{\mathrm{T}}$ is the transepithelial water flow $\left(\mathrm{cm}^{3} / \mathrm{s}\right), \mathrm{S}$ is the surface area $\left(\mathrm{cm}^{2}\right), V_{W}$ is the partial molal volume of water $\left(0.018 \mathrm{~cm}^{3} / \mathrm{mM}\right)$, and $\Delta[\pi]^{\mathrm{T}}$ is the transepithelial osmotic gradient $\left(\mathrm{mosM} / \mathrm{cm}^{3}\right)$.

Measurement of transapical water flow. For measurements of apical membrane osmotic water permeability $\left(\mathrm{P}_{\mathrm{f}}^{\mathrm{A}}\right)$, the $\mathrm{T}$-Cols bearing HBE cultures were placed directly on the coverslip. This maneuver eliminated serosal liquid available for transepithelial water flow. Transapical water flow was determined from the resulting change in epithelial height in response to luminal challenges, as already detailed here. $\mathrm{P}_{\mathrm{f}}{ }^{\mathrm{A}}$ was calculated similar to $\mathrm{P}_{\mathrm{f}}^{\mathrm{T}}$, taking the change in epithelial height as $\mathrm{J}_{\mathrm{v}}{ }^{\mathrm{A}}$ and $\Delta[\pi]$ as the transapical membrane gradient.

Mercury sensitivity of $P_{f}^{T}$ and $P_{f}^{A}$. After baseline measurements of $\mathrm{P}_{\mathrm{f}}^{\mathrm{A}}$ or $\mathrm{P}_{\mathrm{f}}^{\mathrm{T}}$, cultures were incubated luminally with TBR containing $1 \mathrm{mM} \mathrm{HgCl} \mathrm{m}_{2}$ for 5 minutes. 
The $\mathrm{P}_{\mathrm{f}}$ measurements were repeated after substitution of the luminal solution hyperosmotic TBR $\left(-\mathrm{HgCl}_{2}\right)$, and again after a 30-minute luminal incubation with DMEM/F12 containing $5 \mathrm{mM} \beta$-mercaptoethanol in an attempt to reverse the effects of $\mathrm{Hg}$.

Measurement of $P_{f}^{A}$ with and without a serosal bath. To compare values of $\mathrm{P}_{\mathrm{f}}^{\mathrm{A}}$ in the same cultures with the two techniques just described, $\mathrm{P}_{\mathrm{f}}{ }^{\mathrm{A}}$ was measured in three HBE cultures in response to luminal hypertonicity (+150 mosM raffinose) with a serosal bath and subsequently without the bath, i.e., T-Col placed directly on a coverslip.

Response of airway epithelia to serosal bypertonicity. The responses of lumen-facing columnar cells and the basal/intermediate cells to a serosal hyperosmotic challenge were measured. Two protocols that both raised serosal osmolality with raffinose additions were performed in which the T-Cols were placed directly on the coverslip without the trineedle spacers. In the first protocol, the serosal bath was changed, as images were being continuously acquired, by adding $100 \mu \mathrm{L} \mathrm{TBR}+$ $150 \mathrm{mM}$ raffinose to one side of the T-Col while carefully aspirating the initial solution from the opposite side. In the second protocol (see Figure 5), the serosal bath was changed by lifting the T-Col, gently blotting its underside, and then setting it back down on the coverslip bottom of the chamber onto a new droplet of $\mathrm{TBR}+150 \mathrm{mM}$ raffinose. Xz laser scanning was initiated just before replacement of the T-Col; hence, the first image was collected 1-3 seconds after exposure to the hyperosmotic bath.

Data presentation and analysis. The data are presented as the mean \pm SE for $n$ cultures. For each experimental protocol, cultures derived from two or more patients were used. Differences between means were tested for statistical significance using the $t$ test, with grouped or paired data as appropriate to the experiment. From such comparisons, differences yielding $P \leq 0.05$ were judged to be significant.

\section{Results}

Calibration of the measurement system. Figure 1a shows the relationship between fluorescence emission measured by the confocal microscope and the concentration of the fluorescent indicator (TR-dextran) in bulk solution. As expected, the instrument exhibited a linear response to increasing TR-dextran concentration. A calibration of the relationship between the height of a measured serosal volume between the coverslip and the $\mathrm{T}$-Col support is shown in Figure 1b. The confocal images corresponding to four different volumes comprising the serosal bath are shown along with the height-volume relationship for the T-Col support.

The HBE cultures used for these $\mathrm{P}_{\mathrm{f}}$ studies possessed a highly differentiated mucociliary phenotype (Figure 2a). The cultured HBE epithelium was pseudostratified with basal cells positioned between lumen-facing ciliated columnar cells and the T-Col substratum. About half the cultures also possessed cells lying between the columnar and basal cells; these "intermediate cells" can be identified easily in Figure $2 \mathrm{a}$. Figure $2 \mathrm{~b}$ shows a pair of xz-scanning confocal images of a living HBE culture labeled with calcein. The serosal bath is identified as the TR-dextran containing, red-orange space between the T-Col support (intense red-orange fluorescence), and the glass coverslip (black). The image on the right displays the same preparation 60 seconds after the luminal osmolality was increased by 150 mosM with $\mathrm{NaCl}$ (total $=450 \operatorname{mosM})$. Note that the height of the serosal bath decreased and the concentration of the red fluorescent dye increased, indicating a net flow of water out of the serosal bath. Also note the reduction in the epithelial height and the increase in calcein fluorescence, indicating a net flow of water from the cells to the lumen. Although either of these latter measures

a.

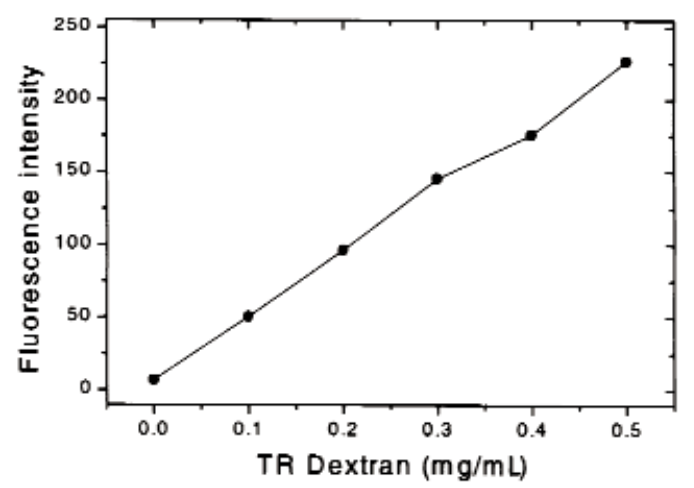

b
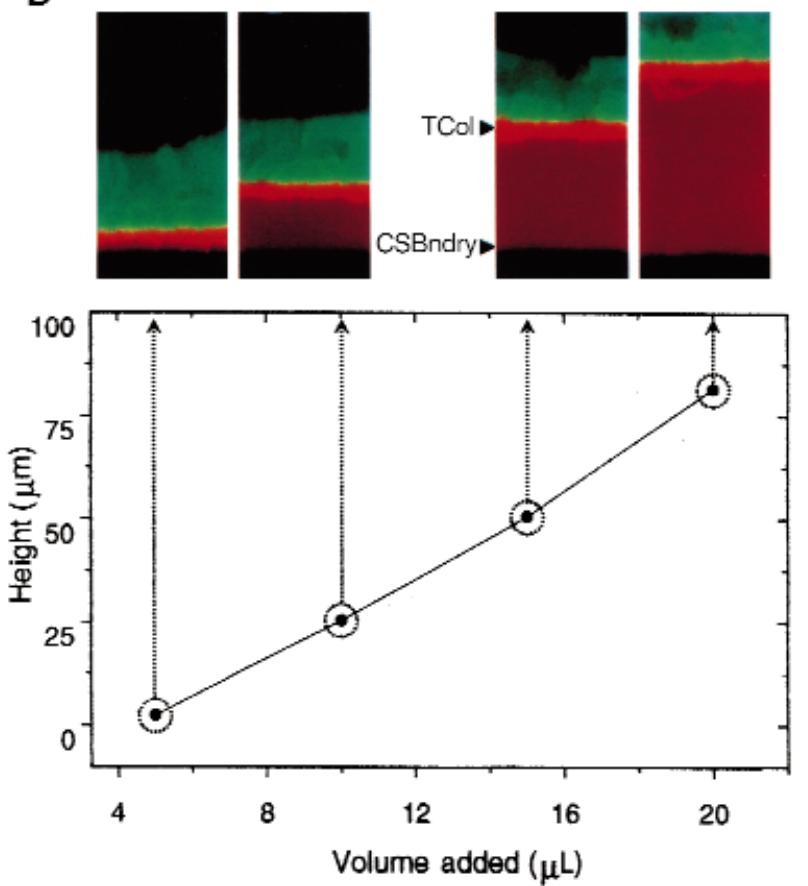

Figure 1

Fluorescence and height measurements by $x z$ laser scanning confocal microscopy. (a) Relationship between Texas Red-dextran concentration and fluorescence. (b) Relationship between serosal bath volume and height. $\mathrm{T}-\mathrm{Col}=$ Transwell-Col substratum, CSBndry = coverslip-serosal bath interface. 
could be used to determine changes in cell volume, in practice we used epithelial height rather than calcein fluorescence owing to the susceptibility of calcein to bleaching. The kinetics of the changes in serosal bath height and TR-dextran concentration during a luminal hyperosmotic challenge for a single experiment are shown in Figure 2c. As indicated by these independent measures of change in serosal bath volume, a linear rate of volume flow was established early after the solution change and was maintained at a steady rate over the 60second period of observation. The changes in serosal bath volume assessed from changes in its height and TR-dextran fluorescence were the same.

Transepithelial and transapical osmotic water permeabilities of normal airway epithelia. Figure 3a summarizes transepithelial $\mathrm{P}_{\mathrm{f}}$ values determined from the application of luminal hyperosmotic $\mathrm{NaCl}$ solutions to normal $\mathrm{HBE}$ cultures and to MDCK cells. $\mathrm{P}_{\mathrm{f}}^{\mathrm{T}}$ for normal airway epithelia, $168.6 \pm 24.3 \mu \mathrm{m} / \mathrm{s}(n=8)$, was more than tenfold higher than MDCK cell $\mathrm{P}_{\mathrm{f}}^{\mathrm{T}}$. In HBE cultures exposed to luminal raffinose (see later here), $\mathrm{P}_{\mathrm{f}}^{\mathrm{T}}$ was $220 \pm 9.8(n=6)$. This value for $\mathrm{P}_{\mathrm{f}}^{\mathrm{T}}$ was significantly different from $\mathrm{P}_{\mathrm{f}}^{\mathrm{T}}$ in response to $\mathrm{NaCl}$ challenge, suggesting a reflection coefficient $\left(\sigma_{\mathrm{NaCl}}\right)$ for $\mathrm{NaCl}$ relative to raffinose of approximately 0.8 . With either solute, $\mathrm{P}_{\mathrm{f}}^{\mathrm{T}}$ is relatively high in comparison to other epithelia.

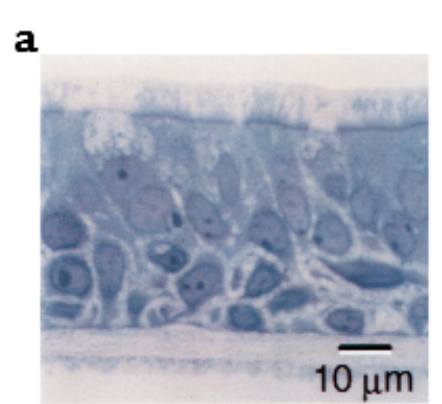

c

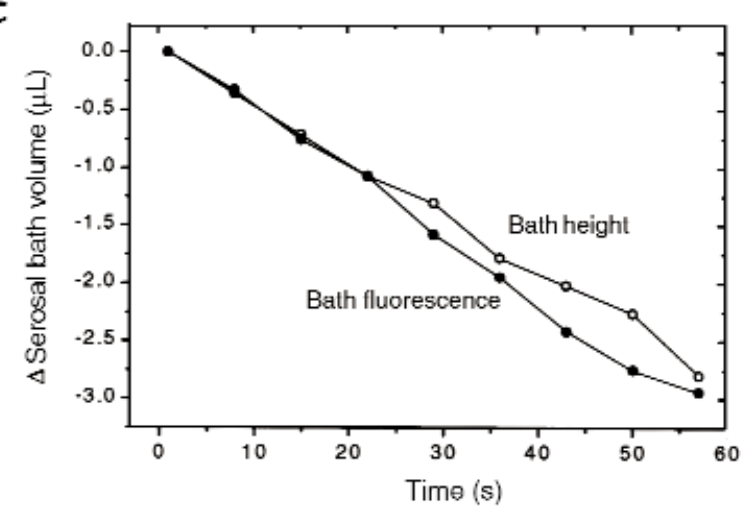

Figure 2

Responses of HBE cell cultures to luminal hypertonicity. (a) Highly differentiated HBE cell culture, typical of those used in study. (b) Xz scanning laser confocal images of an HBE passage 1 cell culture before and 60 seconds after elevation of luminal osmolality to 450 mosM with $\mathrm{NaCl}$. (c) Time course of changes in serosal bath Texas Red-dextran fluorescence and height after luminal hyperosmotic challenge.
A small, but reproducible and significant, decrement in $\mathrm{P}_{\mathrm{f}}^{\mathrm{T}}$ was observed after a 5-minute treatment with $\mathrm{HgCl}_{2}(1 \mathrm{mM})$. In these experiments (and those for apical membrane $\mathrm{Hg}$ sensitivity; see later here), the $\mathrm{Hg}$ effect was poorly reversible, even after washing with solutions containing $\beta$-mercaptoethanol. Addition of $\mathrm{HgCl}_{2}$ to the basolateral surface induced no reproducible changes in transepithelial $\mathrm{P}_{\mathrm{f}}(n=5$; data not shown).

The pattern of results for measurements of transapical $P_{f}$ in normal HBE cell cultures (Figure $3 b$ ) were similar to those for transepithelial flow. $\mathrm{P}_{\mathrm{f}}^{\mathrm{A}}$ in HBE cells exceeded that for MDCK cells, and it also was partially $\mathrm{Hg}$ sensitive. The absolute value for $\mathrm{P}_{\mathrm{f}}^{\mathrm{A}}(86.5 \pm 9.6$ $\mu \mathrm{m} / \mathrm{s})$ in these experiments was less than $\mathrm{P}_{\mathrm{f}}^{\mathrm{T}}(168.6 \pm$ $24.3 \mu \mathrm{m} / \mathrm{s}$ ); possible reasons for this difference are discussed later here. $\mathrm{P}_{\mathrm{f}}^{\mathrm{A}}$ values determined with $\mathrm{NaCl}$ as the osmotic agent were not significantly different from those determined in an identical protocol using raffinose $(96.0 \pm 6.1 \mu \mathrm{m} / \mathrm{s} ; n=6)$, which suggests a $\mathrm{NaCl}$ reflection coefficient for transapical water flow close to unity (numerically, $\sigma_{\mathrm{NaCl}}=0.9$, assuming $\sigma_{\text {raffinose }}=1.0$ ).

Osmotic permeabilities in CF. The osmotic permeabilities for transepithelial and transapical water flow were also determined in cultured $\mathrm{CF}$ airway epithelia using $\mathrm{NaCl}$ to increase luminal osmolality. Like normal airway epithelia, the values of $\mathrm{P}_{\mathrm{f}}^{\mathrm{T}}$ and $\mathrm{P}_{\mathrm{f}}^{\mathrm{A}}$ were relatively high: $242.8 \pm 31.5(n=5)$ and $80.9 \pm 10.7(n=5) \mu \mathrm{m} / \mathrm{min}$, respectively. Because of the poor reversibility of the procedure and fewer available $\mathrm{CF}$ cultures, only the $\mathrm{Hg}$ sensitivity of $\mathrm{P}_{\mathrm{f}}^{\mathrm{T}}$ was determined. Like normal HBE cell cultures, transepithelial $\mathrm{P}_{\mathrm{f}}$ in CF was modestly, but significantly, sensitive to $\mathrm{Hg}: \mathrm{P}_{\mathrm{f}}^{\mathrm{T}}$ was reduced $34 \%$ from $242.8 \pm 31.5$ to $159.5 \pm 46.7(P<0.05$, paired $t$ test $;=6)$.

Kinetic response of airway epithelia to luminal hypertonicity. To investigate more fully the relationships between the water flow across the apical membrane and that across the epithelium, normal HBE cultures were imaged by xz confocal scanning before and after the addition of $150 \mathrm{mM}$ raffinose to the lumen. Care was taken during these experiments to ensure that the entire epithelium and serosal bath were imaged throughout the osmotic response, and the resulting images were analyzed for changes in epithelial height and serosal bath volume (TR-dextran fluorescence).

The height of the epithelium declined rapidly after the luminal addition of raffinose, with a steady-state height achieved at 30-40 seconds after addition of raffinose (Figure 4). $\mathrm{P}_{\mathrm{f}}^{\mathrm{A}}$, calculated from a least-squares fit to the three points between 3 and 12 seconds, was 240 $\mu \mathrm{m} / \mathrm{s}$, a value higher than that measured in the absence of a serosal bath (see earlier here). Serosal TR-dextran fluorescence changed more quickly than cell volume after raffinose addition: steady-state transepithelial water flow was established in 10 seconds or less. $\mathrm{P}_{\mathrm{f}}^{\mathrm{T}}$, calculated from the linear phase of the $\Delta$ TR-dextran fluorescence curve was $220 \mu \mathrm{m} / \mathrm{s}$.

Only the lumen-facing columnar cells experienced a large loss of volume during the osmotic response. Neither basal cells in pseudostratified epithelial cultures, 


\section{Figure 3}

Osmotic permeabilities of HBE cultures. (a) Transepithelial osmotic permeability $\left(\mathrm{P}_{\mathrm{f}}^{\mathrm{T}}\right)$ for $\operatorname{MDCK}(n=5)$ and for $\operatorname{HBE}$ (passage $1 ; n=8$ ) cell cultures challenged luminally with $150 \operatorname{mos} \mathrm{M} \mathrm{NaCl}$, as determined from changes in TR-dextran fluorescence of the serosal bath. (b) Transapical osmotic permeability $\left(\mathrm{P}_{\mathrm{f}}^{\mathrm{A}}\right)$ for $\operatorname{MDCK}(n=5)$ and for HBE (passage $1 ; n=8$ ) cell cultures, as determined from changes in cell height. In both panels, data are expressed as mean $\pm \mathrm{SE}$, and for $n$ HBE cell cultures, without and with luminal $1 \mathrm{mM} \mathrm{HgCl}_{2} .{ }^{A} P<$ 0.05 , paired $t$ test.

nor the intermediate cells lying between these two layers in multilayered cultures (Figure 2a), exhibited significant changes in height or calcein fluorescence during the osmotic response (data not shown). To determine the magnitude of columnar cell shrinkage, the heights of three clearly identifiable cells in each culture were measured in images taken before, and at 48 seconds after, the luminal hyperosmotic challenge. In the six cultures studied, the mean cell height declined from $28.7 \pm 0.9$ to $20.3 \pm 0.6 \mu \mathrm{m}$. One explanation of the nearly perfect osmotic response of the columnar cells to a luminal anisosmotic challenge and the lack of volume changes in basal/intermediate cells is that columnar cell $\mathrm{P}_{\mathrm{f}}^{\mathrm{A}}$ exceeded basolateral membrane $\mathrm{P}_{f}\left(\mathrm{P}_{\mathrm{f}}^{B}\right)$ by a large magnitude and, consequently, that a large osmotic gradient existed across the basolateral membrane. Alternately, the observation could be the result of large unstirred layers in the serosal aspect of the epithelium.

Values for $P_{f}^{A}$ with and without a serosal bath. The mean ratio of $\mathrm{P}_{\mathrm{f}}^{\mathrm{A}}$ for three individual HBE cultures measured on the same day with, and subsequently without, a serosal bath was $1.2 \pm 0.3$.

Response of airway epithelia to serosal hypertonicity. To test whether columnar cell $\mathrm{P}_{\mathrm{f}}^{\mathrm{A}}>>\mathrm{P}_{\mathrm{f}}^{\mathrm{B}}$, as suggested earlier here and by previous work from this laboratory (19), the serosal solution bathing four cultures was exchanged for one made hyperosmotic by the addition of $150 \mathrm{mM}$ raffinose. When T-Cols were lifted and replaced in the chamber into a $20-\mu \mathrm{L}$ droplet of hyperosmotic medium on the coverslip after initiating xz-laser scanning, the height of the lumen facing columnar cells was unchanged, whereas the basal/intermediate cells shrank to new steady-state volume over a period of about 30 seconds (Figure 5). Similar results were observed when the solution change was effected by drawing the hyperosmotic solution beneath the T-Col (data not shown). Consequently, the rate-limiting barrier to transepithelial water flow appears to be the basolateral membrane and the tight junctions of the columnar cells.

\section{Discussion}

Transepithelial and transapical osmotic water permeabilities of cultured airway epithelia. The goal of this study was to test whether the osmotic water permeability of normal airway epithelial cells is relatively high, as observed for epithelia that effect isosmotic volume absorption, or rel- a

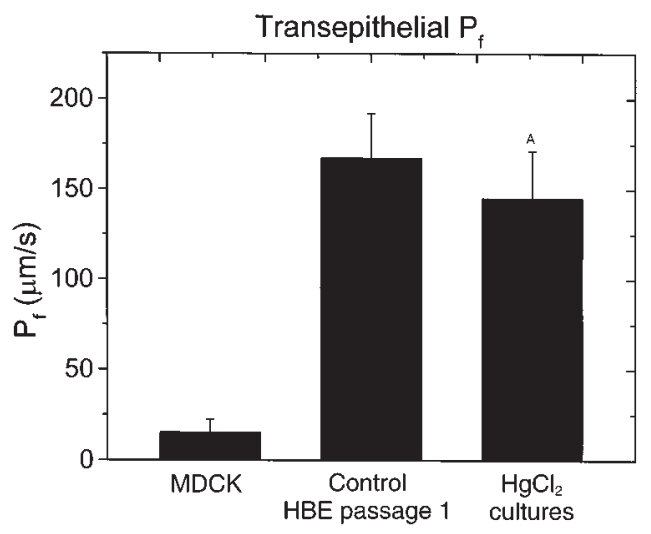

b

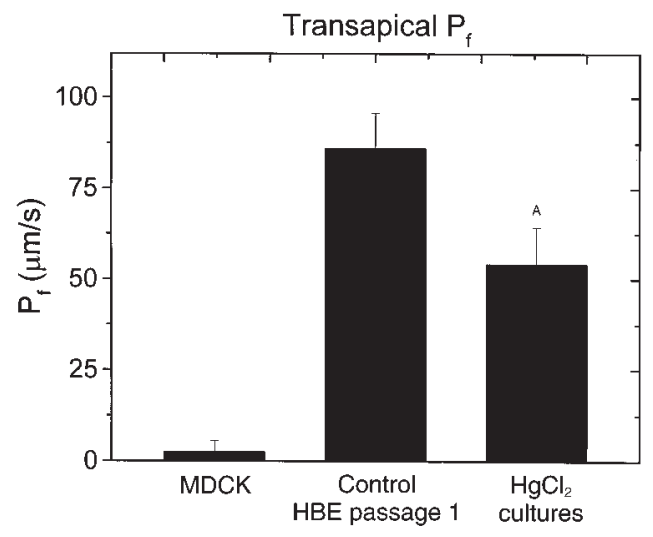

atively low, consistent with epithelia that are relatively impermeable to water and which maintain hyposmotic luminal solutions. In highly differentiated cultures from normal airways, transepithelial osmotic permeability ranged between $168.6 \pm 24.3 \mu \mathrm{m} / \mathrm{s}(\mathrm{NaCl})$ and $220 \pm 9.8 \mu \mathrm{m} / \mathrm{s}$ (raffinose). By comparison, these HBE $\mathrm{P}_{\mathrm{f}}^{\mathrm{T}}$ values are more than tenfold higher than those for water flow across relatively water-impermeable epithelia, e.g., MDCK cell cultures and unstimulated vasopressin-responsive epithelia (12-16). The $\mathrm{P}_{\mathrm{f}}^{\mathrm{T}}$ values for HBE compare favorably with values measured in epithelia that exhibit isosmotic absorption, e.g., gallbladder $(20,21)$ and stimulated vasopressin-responsive epithelia (16). The apical membrane and transepithelial $P_{f} v a l-$ ues for $\mathrm{HBE}$ are also well within the range predicted for isosmotic absorption derived from thermodynamic models of airway epithelial ion and water transport (22, 23). Hence, we conclude that HBE are moderately water permeable and predict isosmotic ASL physiology.

Assessment of confocal techniques for measurement of osmotic water permeability. The confocal microscopy technique used to measure $\mathrm{P}_{\mathrm{f}}^{\mathrm{T}}$ is novel, conceptually simple, and offers the advantage of visualizing the changes in multiple compartments during osmotic water flow across the epithelium. The technique depends on the ability to measure changes in serosal volume, which was provided by changes in an impermeant fluorescent marker (TR-dextran) and bath height as an independent measure (Figure 2). $\mathrm{P}_{\mathrm{f}}^{\mathrm{A}}$ was 
calculated from changes in cell volume, measured from changes in epithelial height with the assumption that lateral cellular dimensions were unaffected during the initial, linear phase of an osmotic response. Given the narrow dimensions of the intercellular space, this assumption appears reasonable, and there were no obvious increases in cell width during cell shrinkage elicited by luminal hyperosmotic challenges.

The osmotic permeabilities measured, however, may underestimate real values as a result of the following limitations. (a) Serosal and/or cellular water movement into the lumenal bath during the osmotic response could potentially change the osmotic driving forces. (b) The luminal osmotic challenge was delivered as a bolus, so that the osmotic stimulus did not occur as a square wave function. (c) The presence of luminal, cellular, and serosal unstirred layers leads to an underestimation of osmotic permeabilities (24). The first two of these potential problems were unlikely to have caused major underestimates of osmotic water permeabilities. In a typical experiment, for example, the volume of the serosal bath changed by less than $6 \%(2.5 \mu \mathrm{L})$ over the brief amount of time required for the measurement, suggesting that dilution of luminal osmolality and concentration of serosal osmolality contributes a relatively small error. Similarly, the bolus volume applied to the lumen was large $(200 \mu \mathrm{L})$ relative to the ambient volume of the surface liquid $(\cong 2 \mu \mathrm{L}$ ), so that solution compositional changes should have been rapid. The rapid development of a linear transepithelial volume flow supports this contention (Figures 2 and 3). Unstirred layer phenomena, however, probably have greater effects in causing underestimates of osmotic permeabilities (24-26). Because there was no compensation for unstirred layers in the present studies on $\mathrm{HBE}$ cells, the actual values of $\mathrm{P}_{\mathrm{f}}^{\mathrm{T}}$ and $\mathrm{P}_{\mathrm{f}}^{\mathrm{A}}$ in these cells may exceed the $360-550 \mu \mathrm{m} / \mathrm{s}$ values estimated for gallbladder.

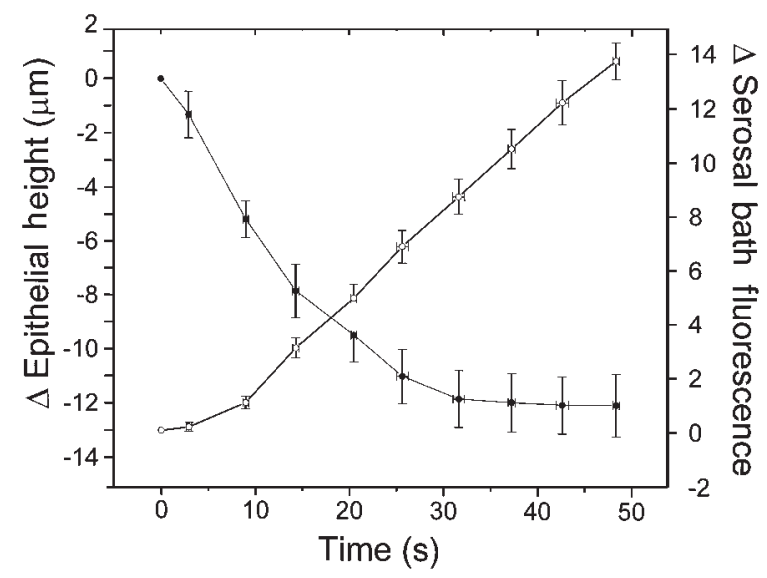

Figure 4

Changes in HBE culture height (filled circles) and serosal volume (open circles) measured simultaneously during luminally directed osmotic water flow. Time courses of changes in epithelial height and serosal bath TR-dextran fluorescence for HBE cultures challenged luminally with 150 mosM raffinose. The data are expressed as the mean $\pm \operatorname{SE}(n=6)$.
A comparison with values of $\mathrm{P}_{\mathrm{f}}^{\mathrm{T}}$ found for cultured HBE cells and $\mathrm{P}_{\mathrm{f}}^{\mathrm{T}}$ for airway epithelia obtained by other techniques, however, supports the general validity of our confocal technique. For example, the values of $\mathrm{P}_{\mathrm{f}}^{\mathrm{T}}$ and $\mathrm{P}_{\mathrm{f}}^{\mathrm{A}}$ we measured are comparable to those reported previously for freshly excised tracheas (67 and 150 $\mu \mathrm{m} / \mathrm{s}$; refs. 27,28$)$ and distal airways $(30-40 \mu \mathrm{m} / \mathrm{s}$; ref. 29) obtained with volume flow and fluorescent techniques, respectively. Also, the values of $\mathrm{P}_{\mathrm{f}}^{\mathrm{T}}$ and $\mathrm{P}_{\mathrm{f}}^{\mathrm{A}}$ measured for MDCK cells were also comparatively low as determined by others $(12,13)$.

We note that the measurement of $\mathrm{P}_{\mathrm{f}}^{\mathrm{A}}$ differed significantly in our two confocal protocols. The original set of experiments with $\mathrm{NaCl}$ as the added luminal osmolyte, which were performed without a macroscopic serosal bath (i.e., no added solution), yielded a value of $86.5 \mu \mathrm{m} / \mathrm{s}$, and with raffinose as the osmolyte under the same conditions it was $96.0 \mu \mathrm{m} / \mathrm{s}$. In a second series of experiments with a macroscopic serosal bath, added raffinose yielded a $\mathrm{P}_{\mathrm{f}}^{\mathrm{A}} 2.5$-fold-higher value at $240 \mu \mathrm{m} / \mathrm{s}$. To test whether the differences in $\mathrm{P}_{\mathrm{f}}^{\mathrm{A}}$ reflected technical differences in the cell culture preparations used for the different experimental protocols, $\mathrm{P}_{\mathrm{f}}^{\mathrm{A}}$ was determined in three cultures in response to hyperosmotic TBR $(+150 \mathrm{mM} \mathrm{NaCl})$ in the presence of a serosal bath, and then again after return to isosmotic conditions and removal of the serosal bath. The ratio of $\mathrm{P}_{\mathrm{f}}^{\mathrm{A}} \pm$ serosal bath was $1.2 \pm 0.3$, indicating that there were no serosal bath-related differences in $\mathrm{P}_{\mathrm{f}}^{\mathrm{A}}$ when the different measuring protocols were used on the same cultures and that the measured differences likely reflect variations in cell culture preparations.

Location of the barrier to transepithelial water flow in a complex epithelium. In previous work (19), we observed that luminal, but not serosal, hyperosmotic exposures caused shrinkage of airway epithelial cell cultures, and postulated that the basolateral membrane was not as water permeable as the apical membrane. In our experiments, we used HBE cell cultures which, like the airway in vivo, differentiate into distinct layers of lumenfacing columnar ciliated and goblet cells and of serosal bath-facing basal/intermediate cells (Figure 2). Exposure of these cultures to luminal hyperosmotic solutions caused columnar cell, but not basal/intermediate cell shrinkage. Hence, it appeared that columnar cell $\mathrm{P}_{\mathrm{f}}^{\mathrm{B}}$ was substantially lower than $\mathrm{P}_{\mathrm{f}}^{\mathrm{A}}$. To test this conclusion, we studied the effects of serosal hypertonicity on the epithelium and found that under these conditions, the basal/intermediate cells, but not the columnar cells, shrank rapidly (Figure 5).

As already noted here, unstirred layers adherent to membranes during osmotic water flows have the effect of diminishing measured osmotic permeabilities $\left(\mathrm{P}_{\mathrm{f}}^{\mathrm{T}}\right.$, $\mathrm{P}_{\mathrm{f}}^{\mathrm{A}}$; ref. 24). These unstirred layers, and those represented by the different cellular and intercellular compartments, basal connective tissue, and the T-Col substratum in the HBE cell cultures, acted to prevent a quantitative partitioning of transepithelial water flow into its component paths. Qualitatively, however, we 


\section{Figure 5}

Hyperosmotic exposure of the basolateral membrane. HBE cultures were exposed serosally to $T B R+150 \mathrm{mM}$ raffinose, by placing the $T$ Col on a droplet of the hyperosmotic medium positioned on the coverslip in the middle of the chamber and then focusing quickly on the epithelium with the confocal microscope in Xz laser scanning mode. The lumen-facing columnar and basal/intermediate cells in the cultures were monitored subsequently for changes in height from images collected at 7-second intervals. The initial image was collected 1-3 seconds from the time of exposure of the culture to the hyperosmotic medium. Within each culture, the heights of three cells of each type were determined in each image series over time, and these data are presented as the mean \pm SE $(n=4)$.

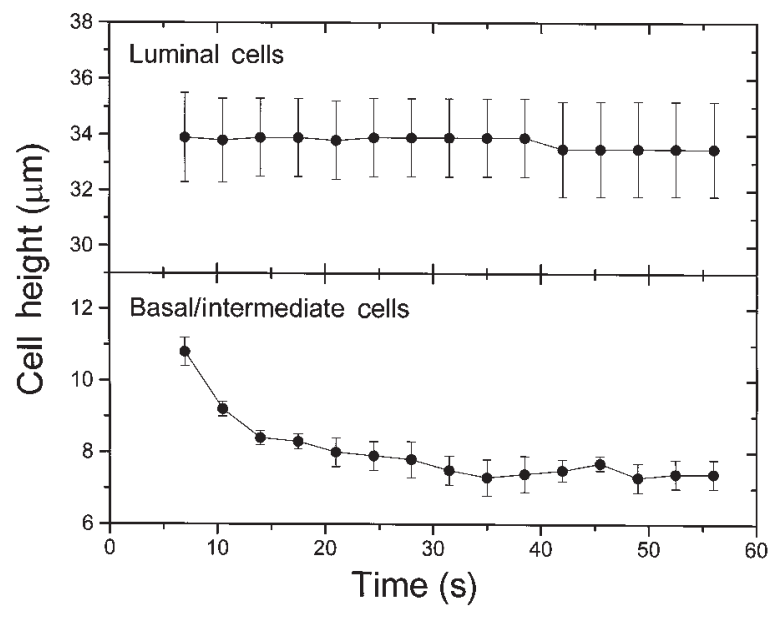

orative water losses occur, we estimate that an average osmotic driving force of only 20 mosM is needed to replenish water lost from airway surfaces during tidal breathing. Not only is the 20 mosM driving force within the range of osmolalities measured on airway surfaces in vivo $(33,34)$, but the actual gradient necessary is overestimated to the degree that unstirred layers have reduced the value determined for $\mathrm{P}_{\mathrm{f}}^{\mathrm{T}}$ (see earlier here). Note that replenishing the water on airway surfaces is energetically quite efficient, not depending on active ion transport mechanisms but rather utilizing the osmotic gradients developed by evaporative water loss from the airway surface liquid compartment.

These data also enable us to understand more completely the complex airway mucosal responses to anisosmotic ASL that occur in vivo during exercise. For example, increased minute ventilation, especially in the presence of "dry" air, leads to increased evaporative water loss from airway surfaces, "dehydrating" the luminal surface and raising ASL osmolality $(33,35)$. As previously discussed here, our data from this (Figures 3, 4, and 5) and previous studies (19) have lead us to conclude that the epithelial cells of the larger airways are configured to sense the osmolality of the luminal bathing medium. Other reports have demonstrated that airway epithelial cells use this osmotic sensing mechanism to trigger release of epithelial-derived factors, sensitive to inhibition of nitric oxide synthase activity (36), to signal the submucosal vasculature to regulate blood flow appropriately (37-39). In support of this notion of an epithelialderived relaxing factor are recent observations showing a luminal hypertonicity-induced relaxation of airway smooth muscle (40), a response that occurs several seconds after the onset of the depolarization of the airway transepithelial potential (41). We speculate that water balance is restored on airway surfaces during periods of increased luminal hypertonicity as a result of airway epithelial cell signaling to submucosal tissues. The relaxation of the microvasculature induces increases in submucosal blood flow, which increases the availability of water in the submucosa to support transepithelial water flow in response to the increased hyperosmotic gradient. 
Relationship to aquaporins. Osmotically driven water flows, both transepithelially and transapically, were reproducibly inhibited by $\mathrm{Hg}$ in normal airway epithelia, though the effects were small $(-20 \%$ to $-30 \%)$ compared with the generally much larger values reported in the literature $(42,43)$. Because of the relatively high osmotic water permeabilities, these data lead us to speculate that the apical membrane of airway epithelia expresses a water channel that is $\mathrm{Hg}$ sensitive, likely in parallel with an $\mathrm{Hg}$-insensitive channel. To date, however, no known aquaporin has been detected by immunological means in the apical membrane of the superficial epithelium of airway epithelia. The water channel aquaporin- 4 has been localized by immunohistochemistry to the basolateral membrane of well-differentiated columnar airway epithelial cells, including those of humans $(29,44)$. The apparent insensitivity of the basolateral barrier to $\mathrm{Hg}$ may be consistent functionally with an aquaporin- 4 channel at this membrane.

The recent report of a coupling between CFTR and aquaporin-3 in coverslip-grown airway cells (45) is intriguing, for it may indicate a new role for CFTR in regulating the water permeability of airway epithelial cell physiology, and a new dysfunction in the CF airway epithelium, namely, reduced water permeability. The absence of aquaporin-3 localization at the site of CFTR expression in the apical membrane of highly differentiated proximal airway epithelial cells, however, suggests a cautious interpretation of these findings (46, 47). Indeed, our data do not support a difference in either $\mathrm{P}_{\mathrm{f}}^{\mathrm{T}}$ or $\mathrm{P}_{\mathrm{f}}^{\mathrm{A}}$ between well-differentiated cultures derived from normal and CF tissues (see Results).

Relationship to airways disease (CF). Our measurements of transepithelial $\mathrm{P}_{\mathrm{f}}$ in normal and $\mathrm{CF}$ cultures have clear-cut implications for analyses of ASL homeostasis in health and disease. With respect to the controversy concerning hyposmotic versus isosmotic airway surface liquids, the measurement of a relatively high transepithelial $\mathrm{P}_{\mathrm{f}}(160-220 \mu \mathrm{m} / \mathrm{s})$ is more consistent with epithelia that maintain isosmotic solutions rather than hyposmotic solutions on their surfaces. Indeed, as pointed out by Novotny and Jakobssen $(22,23)$ and by Farinas et al. (15), even a smaller cellular $\mathrm{P}_{\mathrm{f}}(\sim 41 \mu \mathrm{m} / \mathrm{s})$ is consistent with prediction of isosmotic liquid transport. Thus, the pathogenesis of CF may best be viewed in the context of isosmotic ASL homeostasis, consistent with recent direct measurements of ASL composition suggesting that airway secretions are generally isosmotic $(6,48,49)$.

Conclusions. In summary, these studies demonstrate that airway epithelia exhibit relatively high osmotic water permeabilities. The high values of $\mathrm{P}_{\mathrm{f}}^{\mathrm{T}}$ are most consistent with isosmotic, not hyposmotic, airway surface liquid. The epithelial water permeability reflects, in part, the activity of apical cell membrane Hg-sensitive water channels. Further, our data suggest that airway epithelial cells sense luminal anisosmotic conditions by passive changes in their volume (reflecting the high values of $\mathrm{P}_{\mathrm{f}}$ for the columnar cell apical mem- brane, relative to the basolateral membrane), and we speculate that they actively signal the submucosal vasculature to increase blood flow and thereby increase the availability of water for osmotic water flow. The water-permeable epithelium then passively conducts bulk transepithelial osmotic water flow to the lumen to return ASL to a nearly isosmolar state.

\section{Acknowledgments}

The authors express their appreciation to J.T. Gatzy, C.U. Cotton, E. Hviid-Larsen, and K. Spring for useful discussions. The work was supported by the National Institutes of Health (HL-42384, HL-34322) and Cystic Fibrosis Foundation(CFF R026).

1. Boucher, R.C. 1994. Human airway ion transport. Part two. Am. J. Respir. Crit. Care Med. 150:581-593.

2. Quinton, P.M. 1994. Viscosity versus composition in airway pathology. Am. J. Respir. Crit. Care Med. 149:6-7.

3. Quinton, P.M. 1990. Cystic fibrosis: a disease in electrolyte transport. FASEB J. 4:2709-2717.

4. Stutts, M.J., et al. 1995. CFTR as a cAMP-dependent regulator of sodium channels. Science. 269:847-850.

5. Boucher, R.C. 1999. Molecular insights into the physiology of the 'thin film' of airway surface liquid. J. Physiol. (Lond.) 516:631-638.

6. Matsui, H., et al. 1998. Evidence for periciliary liquid layer depletion, not abnormal ion composition, in the pathogenesis of cystic fibrosis airways disease. Cell. 95:1005-1015

7.Joris, L., Dab, I., and Quinton, P.M. 1993. Elemental composition of human airway surface liquid in healthy and diseased airways. Am. Rev. Respir. Dis. 148:1633-1637.

8. Smith, J.J., Travis, S.M., Greenberg, E.P., and Welsh, M.J. 1996. Cystic fibrosis airway epithelia fail to kill bacteria because of abnormal airway surface fluid. Cell. 85:229-236.

9. Wine, J.J. 1999. The genesis of cystic fibrosis lung disease. J. Clin. Invest. 103:309-312.

10. Zabner, J., Smith, J.J., Karp, P.H., Widdicombe, J.H., and Welsh, M.J. 1998. Loss of CFTR chloride channels alters salt absorption by cystic fibrosis airway epithelia in vitro. Mol. Cell. 2:397-403.

11. Gilljam, H., Ellin, A., and Strandvik, B. 1989. Increased bronchial chloride concentration in cystic fibrosis. Scand. J. Clin. Lab. Invest. 49:121-124.

12. Delporte, C., et al. 1996. Adenovirus-mediated expression of aquaporin5 in epithelial cells. J. Biol. Chem. 271:22070-22075.

13. Lavelle, J.P., et al. 1997. Low permeabilities of MDCK cell monolayers: a model barrier epithelium. Am. J. Physiol. 273:F67-F75.

14. Mangoo-Karim, R., and Grantham, J.J. 1990. Transepithelial water permeability in an in vitro model of renal cysts. J. Am. Soc. Nephrol. 1:278-285.

15. Farinas, J., Kneen, M., Moore, M., and Verkman, A.S. 1997. Plasma membrane water permeability of cultured cells and epithelia measured by light microscopy with spatial filtering. J. Gen. Physiol. 110:283-296.

16. Verkman, A.S. 1989. Mechanisms and regulation of water permeability in renal epithelia. Am. J. Physiol. 257:C837-C850.

17. Matsui, H., Randell, S.H., Peretti, S.W., Davis, C.W., and Boucher, R.C. 1998. Coordinated clearance of periciliary liquid and mucus from airway surfaces. J. Clin. Invest. 102:1125-1131.

18. Farinas, J., Simanek, V., and Verkman, A.S. 1995. Cell volume measured by total internal reflection microfluorimetry: application to water and solute transport in cells transfected with water channel homologs. Biophys. J. 68:1613-1620.

19. Willumsen, N.J., Davis, C.W., and Boucher, R.C. 1994. Selective response of human airway epithelia to luminal but not serosal solution hypertonicity: possible role for proximal airway epithelia as an osmolality transducer. J. Clin. Invest. 94:779-787.

20. Persson, B.E., and Spring, K.R. 1982. Gallbladder epithelial cell hydraulic water permeability and volume regulation. J. Gen. Physiol. 79:481-505.

21. Cotton, C.U., Weinstein, A.M., and Reuss, L. 1989. Osmotic water permeability of Necturus gallbladder epithelium. J. Gen. Physiol. 93:649-679.

22. Novotny, J.A., and Jakobsson, E. 1996. Computational studies of ionwater flux coupling in the airway epithelium. I. Construction of a model. Am. J. Physiol. 270:C1751-C1763.

23. Novotny, J.A., and Jakobsson, E. 1996. Computational studies of ionwater flux coupling in the airway epithelium. II. Role of specific transport mechanisms. Am. J. Physiol. 270:C1764-C1772.

24. Barry, P.H., and Diamond, J.M. 1984. Effects of unstirred layers on membrane phenomena. Physiol. Rev. 64:763-872. 
25. van Os, C.H., Wiedner, G., and Wright, E.M. 1979. Volume flows across gallbladder epithelium induced by small hydrostatic and osmotic gradients. J. Membr. Biol. 49:1-20.

26. Diamond, J.M. 1979. Osmotic water flow in leaky epithelia. J. Membr. Biol. 51:195-216.

27. Durand, J., Durand-Arczynska, W., and Haab, P. 1981. Volume flow, hydraulic conductivity and electrical properties across bovine tracheal epithelium in vitro: effect of histamine. Pflugers Arch. 392:40-45.

28. Ballard, S.T., Crews, A.D., and Taylor, A.E. 1998. Hydraulic conductivity of porcine tracheal epithelium. Am. J. Respir. Crit. Care Med. 197:A556. (Abstr.)

29. Folkesson, H.G., Matthay, M.A., Frigeri, A., and Verkman, A.S. 1996. Transepithelial water permeability in microperfused distal airways. Evidence for channel-mediated water transport. J. Clin. Invest. 97:664-671.

30. Spring, K.R. 1998. Routes and mechanism of fluid transport by epithelia. Annu. Rev. Physiol. 60:105-119.

31. Schnermann, J., et al. 1998. Defective proximal tubular fluid reabsorption in transgenic aquaporin-1 null mice. Proc. Natl. Acad. Sci. USA. 95:9660-9664.

32. Widdicombe, J.G. 1997. Airway surface liquid: concepts and measurements. In Airway mucus: basic mechanisms and clinical perspectives. D.F. Rogers and M.I. Lethem, editors. Birkhäuser Publishing Ltd. Basel, Switzerland. 1-17.

33. Man, S.F.P., Adams, G.K., III, and Proctor, D.F. 1979. Effects of temperature, relative humidity, and mode of breathing on canine airway secretions. J. Appl. Physiol. 46:205-210.

34. Boucher, R.C., Jr., Bromberg, P.A., and Gatzy, J.T. 1980. Airway transepithelial electric potential in vivo: species and regional differences. J. Appl. Physiol. 48:169-176.

35. Boucher, R.C., Stutts, M.J., Bromberg, P.A., and Gatzy, J.T. 1981. Regional differences in airway surface liquid composition. J. Appl. Physiol. 50:613-620.

36. Smith, T.L., Prazma, J., Coleman, C.C., Drake, A.F., and Boucher, R.C. 1993. Control of the mucosal microcirculation in the upper respiratory tract. Otolaryngol. Head Neck Surg. 109:646-652.

37. Wells, U.M., Hanafi, Z., and Widdicombe, J.G. 1994. Osmolality alters tracheal blood flow and tracer uptake in anesthetized sheep. J. Appl. Physiol. 77:2400-2407.

38. Prazma, J., Coleman, C.C., Schockley, W.W., and Boucher, R.C. 1994. Tracheal vascular response to hypertonic and hypotonic solutions. J. Appl. Physiol. 76:2275-2280.

39. Baile, E.M., Guillemi, S., and Pare, P.D. 1987. Tracheobronchial and upper airway blood flow in dogs during thermally induced panting. $J$. Appl. Physiol. 63:2240-2246.

40. Fedan, J.S., et al. 1999. Osmotic regulation of airway reactivity by epithelium. J. Pharmacol. Exp. Ther. 289:901-910.

41. Dortch-Carnes, J., Van Scott, M.R., and Fedan, J.S. 1999. Changes in smooth muscle tone during osmotic challenge in relation to epithelial bioelectric events in guinea pig isolated trachea. J. Pharmacol. Exp. Ther. 289:911-917.

42. Verkman, A.S., et al. 1996. Water transport across mammalian cell membranes. Am. J. Physiol. 270:C12-C30.

43. Lee, M.D., King, L.S., and Agre, P. 1997. The aquaporin family of water channel proteins in clinical medicine. Medicine (Baltimore). 76:141-156.

44. Misaka, T., et al. 1996. A water channel closely related to rat brain aquaporin 4 is expressed in acid-and pepsinogen-secretory cells of human stomach. FEBS Lett. 381:208-212.

45. Schreiber, R., Nitschke, R., Greger, R., and Kunzelmann, K. 1999. The cystic fibrosis transmembrane conductance regulator activates aquaporin 3 in airway epithelial cells. J. Biol. Chem. 274:11811-11816.

46. Verkman, A.S. 1998. Role of aquaporin water channels in kidney and lung. Am. J. Med. Sci. 316:310-320.

47. Nielsen, S., King, L.S., Christensen, B.M., and Agre, P. 1997. Aquaporins in complex tissues. II. Subcellular distribution in respiratory and glandular tissues of rat. Am. J. Physiol. 273:C1549-C1561.

48. Knowles, M.R., et al. 1997. Ion composition of airway surface liquid of patients with cystic fibrosis as compared to normal and disease-control subjects. J. Clin. Invest. 100:2588-2595.

49. Hull, J., Skinner, W., Robertson, C., and Phelan, P. 1998. Elemental content of airway surface liquid from infants with cystic fibrosis. Am. J. Respir. Crit. Care Med. 157:10-14. 